\title{
Electrochemical Impedance Analysis of Ni/CGO10-Based Electrolyte-Supported Cells
}

\author{
M. Riegraf, ${ }^{a}$ S. Dierickx, ${ }^{b}$ A. Weber, ${ }^{b}$ R. Costa, ${ }^{a}$ G. Schiller, ${ }^{a}$ \\ K. A. Friedrich ${ }^{\mathrm{a}, \mathrm{c}}$ \\ ${ }^{a}$ German Aerospace Centre (DLR), Institute of Engineering Thermodynamics, \\ Pfaffenwaldring 38-40, 70569 Stuttgart, Germany \\ ${ }^{\mathrm{b}}$ Institute for Applied Materials (IAM-WET), Karlsruhe Institute of Technology (KIT), \\ Adenauerring 20b, 76131 Karlsruhe \\ ${ }^{c}$ University of Stuttgart, Institute of Building Energetics, \\ Thermal Engineering and Energy Storage (IGTE), \\ Pfaffenwaldring 31, 70569 Stuttgart, Germany
}

\begin{abstract}
To obtain a better understanding of the behavior of Ni/CGO fuel electrodes, this work presents a comprehensive investigation of $\mathrm{Ni} / \mathrm{CGO} 10$-based electrolyte-supported cells. Commercial $\mathrm{Ni} / \mathrm{CGO} 10|\mathrm{CGO} 10| 3 \mathrm{YSZ}|\mathrm{CGO} 10| \mathrm{Ni} / \mathrm{CGO} 10$-based symmetrical cells were characterized between $550-975{ }^{\circ} \mathrm{C}$ at $p \mathrm{H}_{2}=0.8$ bar and $p \mathrm{H}_{2} \mathrm{O}=0.2$ bar and for different $\mathrm{H}_{2} / \mathrm{H}_{2} \mathrm{O}$ gas mixtures at $550{ }^{\circ} \mathrm{C}$. Small electrode area, thin anodes and large gas flow rates were used to minimize mass transport contributions. The distribution of relaxation times (DRT) is calculated and based on the results, an equivalent circuit model is derived. Electrode process contributions on Ni/CGO were calculated by means of a complex non-linear square fit of the equivalent circuit model to experimental data. One low frequency and one middle frequency electrode process were identified and correlated to a surface and a bulk process, respectively. Apparent activation energy barriers for both processes were derived.
\end{abstract}

\section{Introduction}

One commonly used cell architecture in commercial solid oxide cell (SOC) applications is the electrolyte-supported cell (ESC) design. The fuel electrodes of choice for both fuel cell and electrolysis modes are the nickel/yttria-stabilized zirconia (YSZ) and the nickel/gadoliniumbased ceria (CGO) electrode (1-3).

Important insights into the kinetics of the Ni/YSZ electrode have been achieved by employing electrochemical impedance spectroscopy (EIS) in symmetrical and full cell configurations (4-8). This is facilitated by occurrence of the Ni/YSZ charge transfer process during hydrogen oxidation at high frequencies between $10^{3}-10^{4} \mathrm{~Hz},{ }^{9}$ which enables its clear separation from the lower frequency process of the LSM or LSCF cathode $\left(\sim 10^{2} \mathrm{~Hz}\right)$ and mass transport $\left(10^{0}-10^{1} \mathrm{~Hz}\right)$ contributions $(4,5,8-11)$. Based on EIS measurements and the calculation of the distribution of relaxation times (DRT), the process resistances can be determined by means of a complex non-linear square (CNLS) fit of experimental data to a physically meaningful equivalent circuit model (ECM). Then, by means of systemic investigation of the dependencies of the process resistance contributions on temperature, $p \mathrm{H}_{2} \mathrm{O}$ and $p \mathrm{H}_{2}$, conclusions about the performance and degradation of individual cell components could be deduced and important insights into the mechanistic electrode behavior could be obtained. 
However, this approach has been proven to be more difficult for Ni/CGO10-based cells due to the occurrence of a low frequency electrode process at $\sim 1 \mathrm{~Hz}$, and therefore the convolution of anode, cathode, and mass transport contributions with similar relaxation frequencies $(2,12)$. This low frequency process was attributed to a surface process, most likely the electrode charge transfer reaction (12). Its low frequency was correlated with the occurrence of a large chemical capacitance that originates in the oxygen non-stoichiometry of CGO. This non-stoichiometry is the reason for the mixed ionic and electronic conductivity (MIEC) properties of CGO at high temperature and reducing atmosphere (13-15).

In addition to a low frequency process, a middle frequency process at $10^{2} \mathrm{~Hz}$ has been observed in impedance spectra as well which was suggested to originate from the oxide ion transport from bulk to surface or across the electrolyte/electrode interface. ${ }^{16,17}$ However, a systematic study investigating state-of-the-art Ni/CGO10 symmetrical cells under the careful minimization of mass transfer contributions has not been carried out yet.

Therefore, in the present study the loss mechanisms in Ni/CGO10 fuel electrodes are identified and their contributions are separated by means of the combination of EIS, DRT and a CNLS fit to a developed ECM model. Symmetrical, electrolyte-supported cells are used in order to avoid the convolution of fuel and air electrode. Furthermore, small electrode areas, thin electrodes and large gas flow rates were employed to minimize mass transport contributions.

\section{Experimental Procedure}

All symmetrical cell measurements were carried out with a commercial, state-of-the-art electrolyte-supported cell with dimensions of $12 \times 12 \mathrm{~mm}^{2}$ and an active surface area of $10 \times 10 \mathrm{~mm}^{2}$ (Kerafol, Germany). $25 \mu \mathrm{m}$ thick $\mathrm{Ni} / \mathrm{Ce}_{0.9} \mathrm{Gd}_{0.1} \mathrm{O}_{2-\delta}(\mathrm{CGO} 10)$ electrodes were applied onto a $90 \mu \mathrm{m}$ thick electrolyte, that was coated with $5 \mu \mathrm{m}$ thick CGO10 adhesion layers on both sides. Furthermore, the electrodes contain a current collector layer with increased Ni content. Full cells with the same fuel electrode were characterized in detail by means of current-voltage characteristics, electrochemical impedance spectroscopy and scanning electron microscopy (SEM) in our previous publications $(12,18,19)$.

The cell was mounted in a ceramic cell housing as depicted in Figure 1 and contacted with Ni meshes on both sides (4). As a one-atmosphere setup was employed no sealing between the electrodes was required. The atmosphere in the reactive chamber consisted of $\mathrm{H}_{2} / \mathrm{H}_{2} \mathrm{O} / \mathrm{N}_{2}$ gas mixtures and its composition was measured via a lambda sensor close to the sample. Electrochemical impedance spectroscopy measurements were carried out at OCV to determine the cell resistance. 


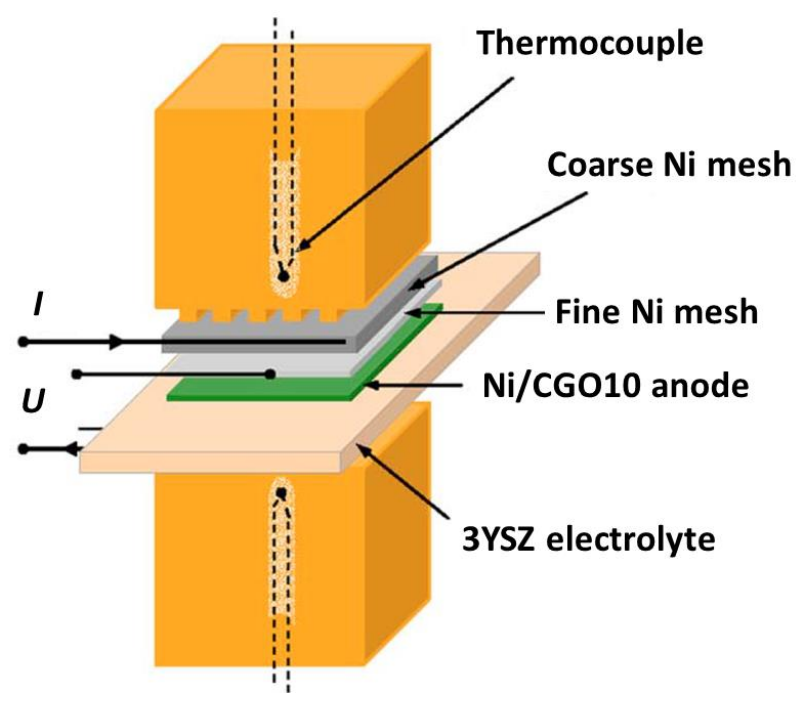

Figure 1: Schematic illustration of the sample holder in the symmetrical cell test bench. Adapted from Sonn et al. (4).

Symmetrical cell measurements are presented that were carried out in the symmetrical cell setup depicted in Figure 1. The cell was tested in a temperature range between $550-975{ }^{\circ} \mathrm{C}$ at steps of $25 \mathrm{~K}$ and at $p \mathrm{H}_{2}=0.8$ bar and $p \mathrm{H}_{2} \mathrm{O}=0.2$ bar. Total gas flow rates was $1 \mathrm{~L} \cdot \mathrm{min}^{-1}$. The combined use of symmetrical cells, small electrode areas, thin electrodes and large gas flow rates is employed to minimize mass transport contributions. This approach was shown to reduce both gas conversion and gas diffusion impedance in the employed setup to a minimum (4).

Impedance spectroscopy was carried out using a Solartron 1260 FRA (frequency response analyzer) at frequencies between $10 \mathrm{mHz}$ and $1 \mathrm{MHz}$. The current amplitudes were chosen for the voltage response not to exceed $12 \mathrm{mV}$ (20). A Kramers Kronig Test was applied to the data to ensure the validity of the measured spectra (21).

\section{Results and Discussion}

In the following, the characterization of the symmetrical cells and their analysis by means of electrochemical impedance spectroscopy and DRT is shown. Based on the results, a simple equivalent circuit model is developed and the experimental data is fitted to the ECM via a CNLS routine. The process resistance values are then determined for all experiments with varying temperature.

Figure 2 shows a typical EIS measurement at a temperature of $550{ }^{\circ} \mathrm{C}$. Two distinguished arcs can be identified, one at $\sim 0.5 \mathrm{~Hz}$ and one at $\sim 10 \mathrm{~Hz}$. Furthermore, the beginning of an additional arc is indicated at frequencies higher than $10^{4} \mathrm{~Hz}$. This high frequency arc corresponds to the resistance within the electrolyte and thus, the interception with the y-axis at $\sim 11.5 \Omega \cdot \mathrm{cm}^{2}$ represents the value of the Ohmic resistance. As polycrystalline electrolytes are employed, in the high frequency range, contributions of the YSZ grain bulk and YSZ grain boundaries appear at low temperatures such as $550{ }^{\circ} \mathrm{C}$ (22). However, in the measured frequency range they cannot be fully resolved. These contributions become decreasingly visible at higher temperature, and therefore are typically not reported in literature. The polarization resistance shows two nearly ideal semicircles. 

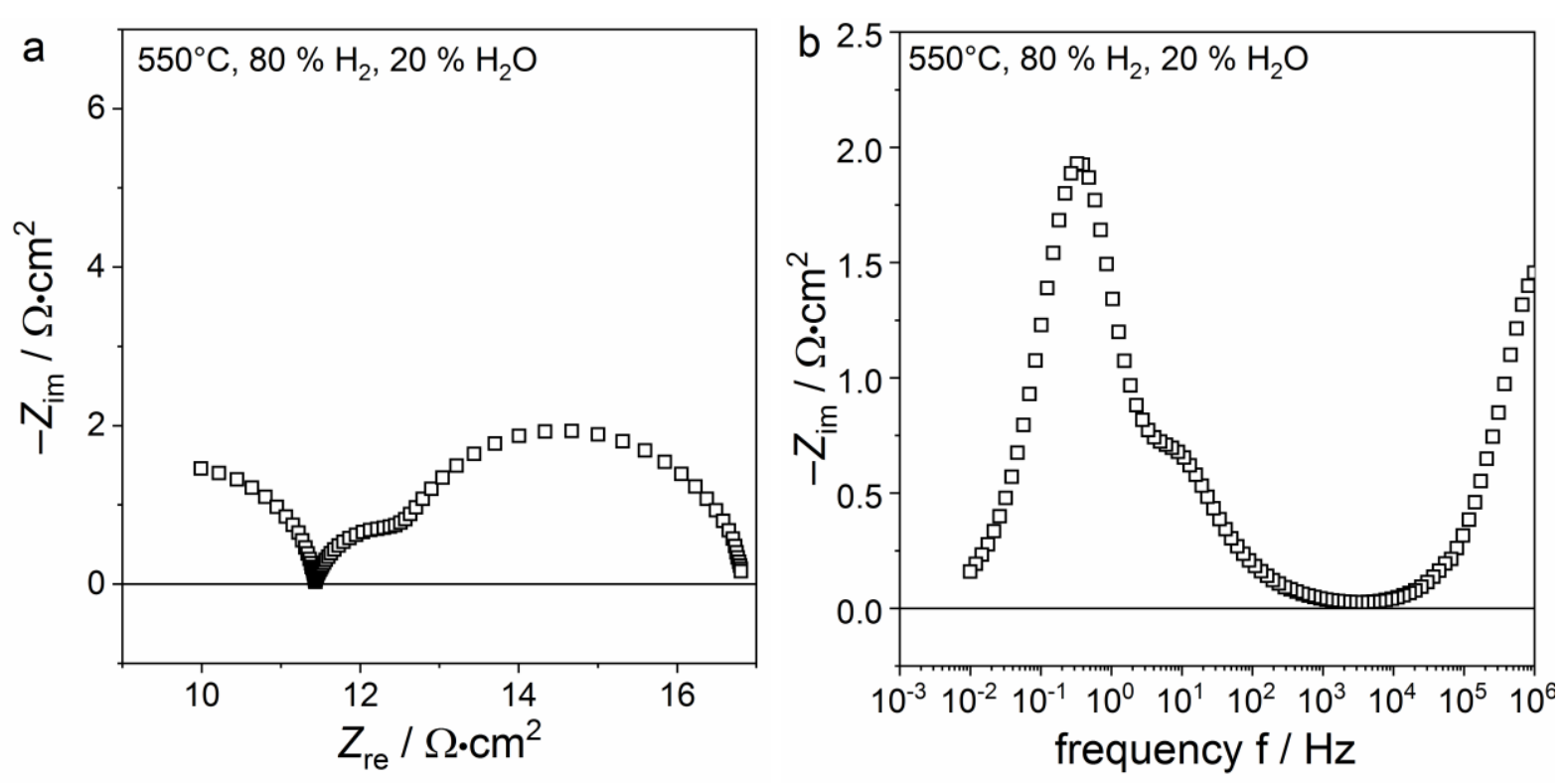

Figure 2. (a) Nyquist plot and (b) imaginary impedance plots at $550{ }^{\circ} \mathrm{C}$. The gas phase composition was at $p \mathrm{H}_{2}=0.8$ bar and $p \mathrm{H}_{2} \mathrm{O}=0.2$ bar.

The DRT calculated for the EIS measurements of the symmetrical cells at $0.8 \mathrm{bar}_{2}$ and 0.2 bar $\mathrm{H}_{2} \mathrm{O}$ and between $550-600{ }^{\circ} \mathrm{C}$ is shown in Figure 3. The discussion of DRT has shown the potential to reveal significantly more insight into the cell behavior than raw impedance data as demonstrated in numerous previous publications $(4,5,7,23,24)$. The calculated DRT suggests two main contributions, one at low frequencies (LF) around $1 \mathrm{~Hz}$ and another at middle frequencies (MF) around $10^{2} \mathrm{~Hz}$, which is consistent with previous studies on Ni/CGO10 electrodes $(17,25)$. No high frequency contribution $>10^{3} \mathrm{~Hz}$ is visible as it is generally observed for Ni/YSZ electrodes $(4,5)$. Both of the contributions are thermally activated as suggested by the shift to lower frequencies with decreasing temperature, and thus, can be attributed to physico-chemical electrode processes. Another middle frequency contribution is visible at $10^{2}-10^{3} \mathrm{~Hz}$. However, as it is negligibly small the two middle frequency elements were therefore modeled with a single RQ element during the CNLS fitting process.

In previous studies of $\mathrm{Ni} / \mathrm{CGO}$ electrodes, the origin of the of the low frequency process was suggested to be an electrode surface process, probably the charge transfer process $(14,25-$ 29). In a MIEC material like CGO this will create a electrostatic surface potential step between charged adsorbates and electronic counter charges in the outmost surface layer of CGO (30,31). The middle frequency process was attributed to a bulk process. Specifically, oxide ion transport from bulk to surface or across the electrolyte/electrode interface has been suggested before $(16,17)$.

As it was not possible to fully resolve the high frequency, capacitive behavior of the electrolyte that is visible at lower temperatures (see Figure 2), the higher frequencies $\left(>10^{4}\right.$ $\mathrm{Hz}$ ) were omitted during the fitting processes and modeled by one simple resistance element that describes the ohmic resistance in electrolyte and adhesion layers. As a result, a simple ECM was applied that includes one resistance element and two RQ elements (describing the two electrode processes).

For Ni/YSZ fuel electrodes, a transmission line model has been shown to provide a more physically meaningful description of the electrode processes, modeling the coupling between ionic conduction pathway in the ceramic electrolyte matrix, electronic conduction pathway in 
the nickel phase and electrochemical reaction at the triple phase boundary $(4,7,8,32)$. This coupling is generally visible as a skewed semicircle with a linear shape at high frequencies that transitions into an attached semicircle at lower frequencies. However, since in the present case the two processes do not seem to be coupled as clearly separated semicircles are present, a transmission line model cannot be applied without further detailed insights into the electrode mechanism.

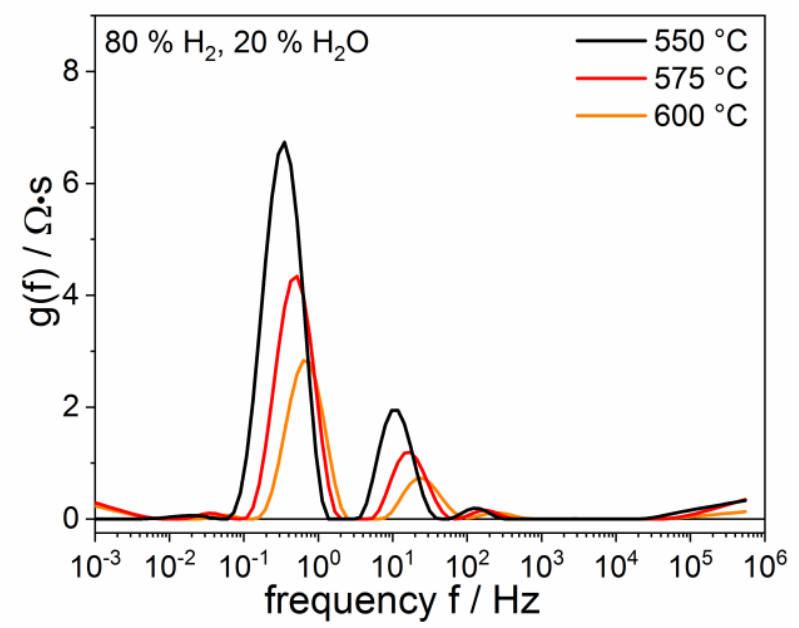

Figure 3. DRT for changing operating temperatures between $550-600{ }^{\circ} \mathrm{C}$. Measurements at higher temperatures were omitted here to increase visibility of the remaining plots. The gas phase composition was kept constant at $p \mathrm{H}_{2}=0.8$ bar and $p \mathrm{H}_{2} \mathrm{O}=0.2$ bar.

The obtained resistance values of the two processes as a function of temperature are depicted in Figure 4. Apparent activation energy barriers for the processes can be extracted by fitting the data to the Arrhenius-type equation:

$$
R_{p}(T)=B \exp \left(\frac{E_{a c t}}{\mathrm{R} T}\right),
$$

where $R_{p}$ is the process resistance, $B$ the pre-exponential factor and $E_{a c t}$ the process apparent activation energy barrier. The fit of the middle frequency process in Figure $4 \mathrm{~b}$ shows a high quality $\left(\mathrm{R}^{2}>0.999\right)$ and yields an apparent activation energy barrier of $1.04 \mathrm{eV}$. The fit for the low frequency process, however, shows a change of slope of the fitted curve (Figure 4a), and, therefore, two temperature regimes with different apparent activation energy barriers. Above $775{ }^{\circ} \mathrm{C}$, the apparent activation energy barrier is identified to be $0.61 \mathrm{eV}$, below $775{ }^{\circ} \mathrm{C}$ it is $1.14 \mathrm{eV}$.

As the low frequency process is thermally activated, it is possible that at temperatures higher than $775{ }^{\circ} \mathrm{C}$, mass transport processes start to significantly contribute to the low frequency resistance as the kinetics of the electrode process are getting faster. This hinders the accurate determination of the low frequency fuel electrode resistance. Gas conversion was shown not to contribute to the impedance in the employed setup due to large gas flow rates and small electrode areas (4). Even though electrodes with thicknesses below $30 \mu \mathrm{m}$ have been suggested to exhibit negligible gas diffusion resistance in the past (33), it is still possible that gas diffusion through the porous electrodes cannot be fully neglected in the present case, especially at higher temperatures. This could also include axial gas diffusion above the porous electrode and diffusion through the contacting mesh (4).

Another possible reason for the different apparent activation energy barrier regimes could be a change in the fuel oxidation mechanism. While early investigations of Ni/CGO have assumed a hydrogen oxidation mechanism at the triple phase boundary similar to the one on 
$\mathrm{Ni}$ /YSZ, numerous later studies have shown the electro-catalytic properties of CGO with regards to hydrogen oxidation and water electrolysis, giving an explanation for its unique characteristics such as high sulfur tolerance despite the presence of an easily-poisoned $\mathrm{Ni}$ phase $(14,15)$.

Different possible fuel oxidation mechanisms were extensively discussed in our previous work, and the possibility of competitive pathways at double phase and triple phase boundary was pointed out $(12,18,19)$. Thus, it is possible that the change in hydrogen oxidation mechanism is the reason for the different slopes in Figure 4a. More detailed investigations on carefully designed patterned electrodes will have to be carried out to shed light on the temperature effect on both double phase and triple phase boundary pathways.
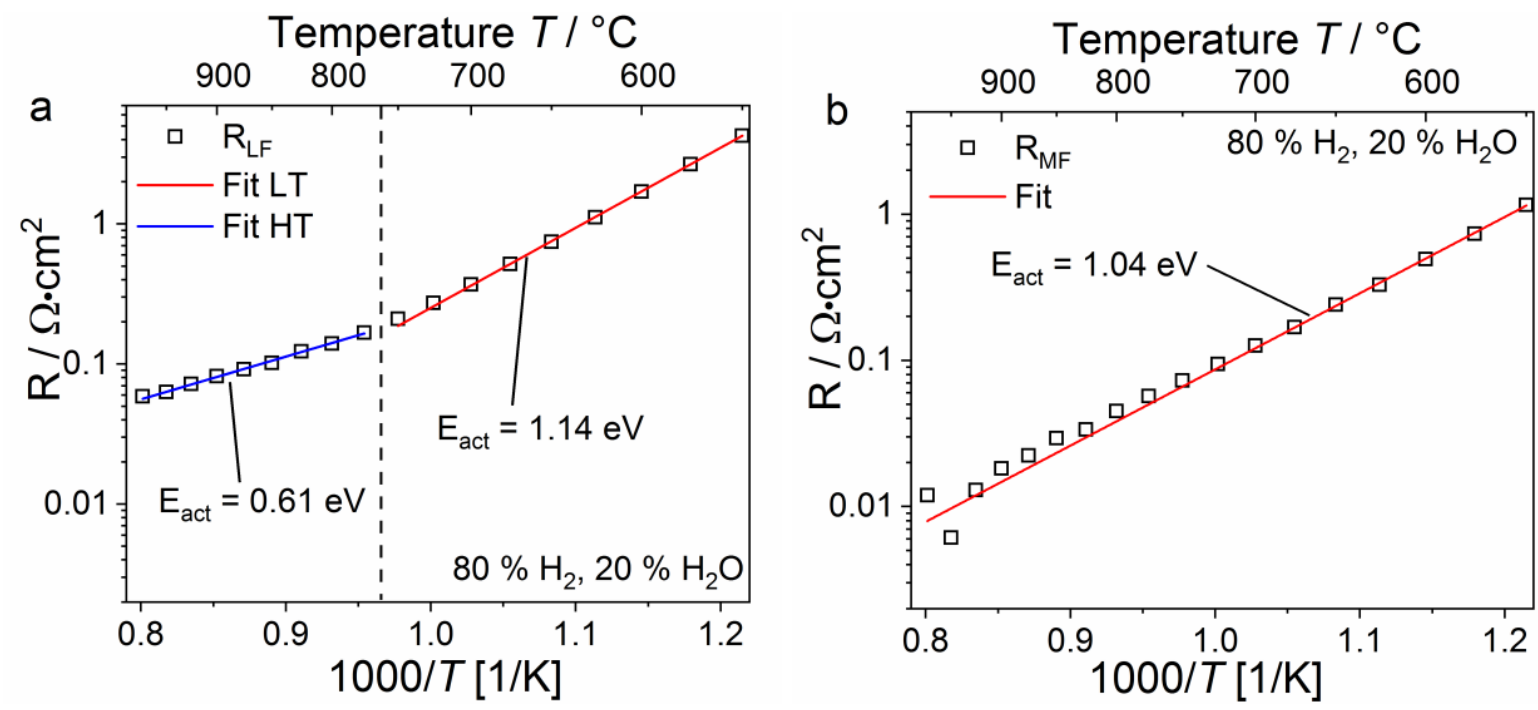

Figure 4. Resistance of (a) the low frequency electrode process, (b) the low frequency process with a subtracted $0.05 \Omega \cdot \mathrm{cm}^{2}$ to account for the gas diffusion resistance. All fits achieved values with $R^{2}>0.999$.

Figure 5a displays the capacitance values associated with the low frequency process. The values of about $\sim 1 \mathrm{~F} \cdot \mathrm{cm}^{-2}$ are significantly larger than the ones generally obtained for Ni/YSZ $\left(\sim 10^{-4} \mathrm{~F} \cdot \mathrm{cm}^{-2}\right)(34,35)$, which clearly illustrates the different nature of the capacitance in $\mathrm{Ni} / \mathrm{CGO}$. The origin is likely a large chemical capacitance, which is associated with a changing $\mathrm{Ce}^{3+} / \mathrm{Ce}^{4+}$ (correlated with a variation in the oxygen stoichiometry in the CGO phase) ratio in the CGO $(14,30,36)$. Although a convolution of the low frequency electrode process and the gas diffusion possibly exists in the present study, at low temperatures the cell behavior must be dominated by the electrode process. The calculated capacitance values increase with temperature. The curve exhibits plateaus at high and low temperatures. Thus, the $\mathrm{Ce}^{3+} / \mathrm{Ce}^{4+}$ ratio determines the chemical capacitance values which stretch over a whole order of magnitude $\left(0.1-1 \mathrm{~F} \cdot \mathrm{cm}^{-2}\right)$. This quantitatively confirms an effect that we already qualitatively observed in sulfur poisoning experiments of $\mathrm{Ni} / \mathrm{CGO}$ electrodes in our recent work (12).

The capacitance of the middle frequency process also shows a similar dependence on the temperature with increasing values $\left(0.02-0.04 \mathrm{~F} \cdot \mathrm{cm}^{-2}\right)$ at higher temperatures, however in a less pronounced manner. 

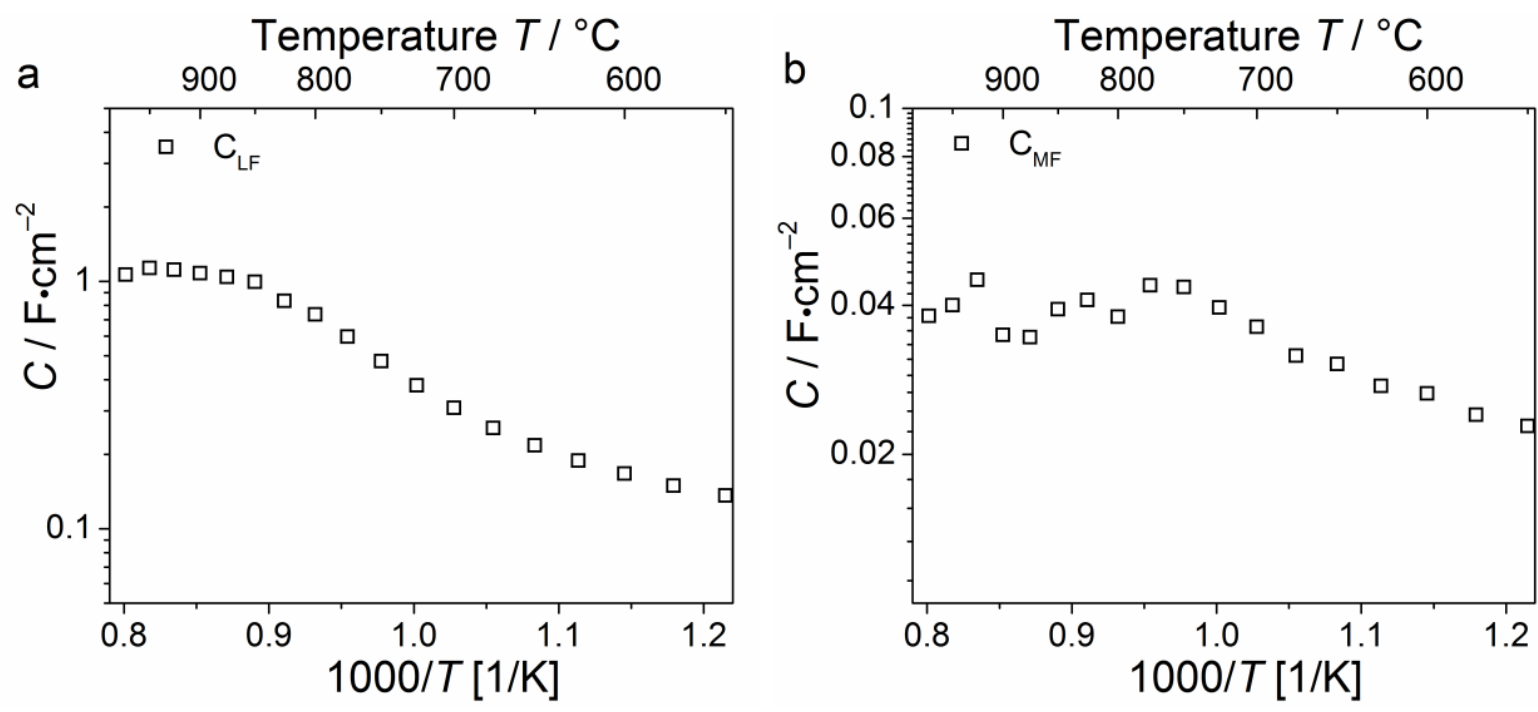

Figure 5. Capacitance of (a) the low frequency electrode process and (b) the middle frequency fuel electrode process as a function of temperature.

\section{Summary and Conclusions}

This work presents a comprehensive electrochemical impedance study of state-of-the-art $\mathrm{Ni} / \mathrm{CGO} 10$-based electrolyte-supported cells. Commercial Ni/CGO10|CGO10|3YSZ-based symmetrical cells were characterized between $550-975{ }^{\circ} \mathrm{C}$ at $p \mathrm{H}_{2}=0.8$ bar and $p \mathrm{H}_{2} \mathrm{O}=0.2$ bar. By employing small electrode areas, thin electrodes and large gas flow rates the effect of mass transport contributions was minimized to clearly identify and separate the electrode process. By means of calculating the DRT, an equivalent circuit model was derived comprising two RQ modeling for the electrode behavior. Electrode process contributions on $\mathrm{Ni} / \mathrm{CGO}$ were calculated by means of a complex non-linear square fit of the equivalent circuit model to experimental data. One low frequency and one middle frequency electrode process were identified. Apparent activation energy barriers of both processes were determined. Moreover, the capacitance of the $\mathrm{Ni} / \mathrm{CGO} 10$ charge transfer process was shown to exhibit a significant dependence on both the operating temperature. This reflects the existence of a large chemical capacitance with a changing $\mathrm{Ce}^{3+}$ concentration in CGO.

\section{Acknowledgments}

We gratefully acknowledge financial support by the German Ministry of Education and Research within the framework of the project "SOFC-Degradation: Analyse der Ursachen und Entwicklung von Gegenmaßnahmen" via grant number 03SF0494C.

\section{References}

1. A. Mai, B. Iwanschitz, U. Weissen, R. Denzler, D. Haberstock, V. Nerlich, J. Sfeir, and A. Schuler, ECS Trans., 25(1), 149 (2009).

2. M. Kusnezoff, N. Trofimenko, M. Müller, and A. Michaelis, Materials, 9, 906 (2016).

3. A. Glauche, T. Betz, and M. Ise, ECS Trans., 35(1), 157 (2011).

4. V. Sonn, A. Leonide, and E. Ivers-Tiffée, J. Electrochem. Soc., 155, B675 (2008).

5. A. Leonide, V. Sonn, A. Weber, and E. Ivers-Tiffée, J. Electrochem. Soc., 155, B36 (2007).

6. A. Hagen, R. Barfod, P. V. Hendriksen, Y.-L. Liu, and S. Ramousse, J. Electrochem. Soc., 
153, A1165 (2006).

7. S. Dierickx, J. Joos, A. Weber, and E. Ivers-Tiffée, Electrochim. Acta, 265, 736 (2018).

8. S. Dierickx, T. Mundloch, A. Weber, and E. Ivers-Tiffée, J. Power Sources, 415, 69 (2019).

9. A. Kromp, A. Leonide, A. Weber, and E. Ivers-Tiffée, J. Electrochem. Soc., 158, B980 (2011).

10. M. P. Hoerlein, M. Riegraf, R. Costa, G. Schiller, and K. A. Friedrich, Electrochim. Acta, 276, 162 (2018).

11. W. G. Bessler and S. Gewies, J. Electrochem. Soc., 154, B548 (2007).

12. M. Riegraf, V. Yurkiv, R. Costa, G. Schiller, and K. A. Friedrich, ChemSusChem, 10, 587 (2017).

13. C. Zhang, M. E. Grass, A. H. McDaniel, S. C. Decaluwe, F. El Gabaly, Z. Liu, K. F. McCarty, R. L. Farrow, M. A. Linne, Z. Hussain, G. S. Jackson, H. Bluhm, and B. W. Eichhorn, Nat. Mater., 9, 944 (2010).

14. T. Nakamura, T. Kobayashi, K. Yashiro, A. Kaimai, T. Otake, K. Sato, J. Mizusaki, and T. Kawada, J. Electrochem. Soc., 155, B563 (2008).

15. W. C. Chueh, Y. Hao, W. Jung, and S. M. Haile, Nat. Mater., 11, 155 (2012).

16. S. Primdahl and Y. L. Liu, J. Electrochem. Soc., 149, A1466 (2002).

17. S. Primdahl and M. Mogensen, Solid State Ionics, 152-153, 597 (2002).

18. M. Riegraf, M. Hoerlein, R. Costa, G. Schiller, and K. A. Friedrich, ACS Catal., 7, 7760 (2017).

19. M. Riegraf, A. Zekri, M. Knipper, R. Costa, G. Schiller, and K. A. Friedrich, J. Power Sources, 380, 26 (2018).

20. D. Klotz, A. Weber, and E. Ivers-Tiffée, Electrochim. Acta, 227, 110 (2017).

21. M. Schönleber, D. Klotz, and E. Ivers-Tiffée, Electrochim. Acta, 131, 20 (2014).

22. J. Nielsen and J. Hjelm, Electrochim. Acta, 115, 31 (2014).

23. A. Weber, S. Dierickx, A. Kromp, and E. Ivers-Tiffée, Fuel Cells, 13, 487 (2013).

24. A. Kromp, S. Dierickx, A. Leonide, A. Weber, and E. Ivers-Tiffée, J. Electrochem. Soc., 159, B597 (2012).

25. P. Kim, D. J. L. Brett, and N. P. Brandon, J. Power Sources, 189, 1060 (2009).

26. A. Babaei, S. P. Jiang, and J. Li, J. Electrochem. Soc., 156, B1022 (2009).

27. M. Chen, B. H. Kim, Q. Xu, B. G. Ahn, and D. P. Huang, Solid State Ionics, 181, 1119 (2010).

28. Z. A. Feng, F. El Gabaly, X. Ye, Z. X. Shen, and W. C. Chueh, Nat. Commun., 5, 1 (2014).

29. W. C. Chueh, Y. Hao, W. Jung, and S. M. Haile, Nat. Mater., 11, 155 (2012).

30. W. C. Chueh and S. M. Haile, Annu. Rev. Chem. Biomol. Eng., 3, 313 (2012).

31. J. Fleig, Phys. Chem. Chem. Phys., 7, 2027 (2005).

32. B. A. Boukamp, Electrochim. Acta, 154, 35 (2015).

33. S. Primdahl and M. Mogensen, J. Electrochem. Soc., 146, 2827 (1999).

34. M. Vogler, A. Bieberle-Hütter, L. Gauckler, J. Warnatz, and W. G. Bessler, J. Electrochem. Soc., 156, B663 (2009).

35. W. G. Bessler, M. Vogler, H. Störmer, D. Gerthsen, A. Utz, A. Weber, and E. IversTiffée, Phys. Chem. Chem. Phys., 12, 13888 (2010).

36. J. Fleig, Phys. Chem. Chem. Phys., 7, 2027 (2005). 